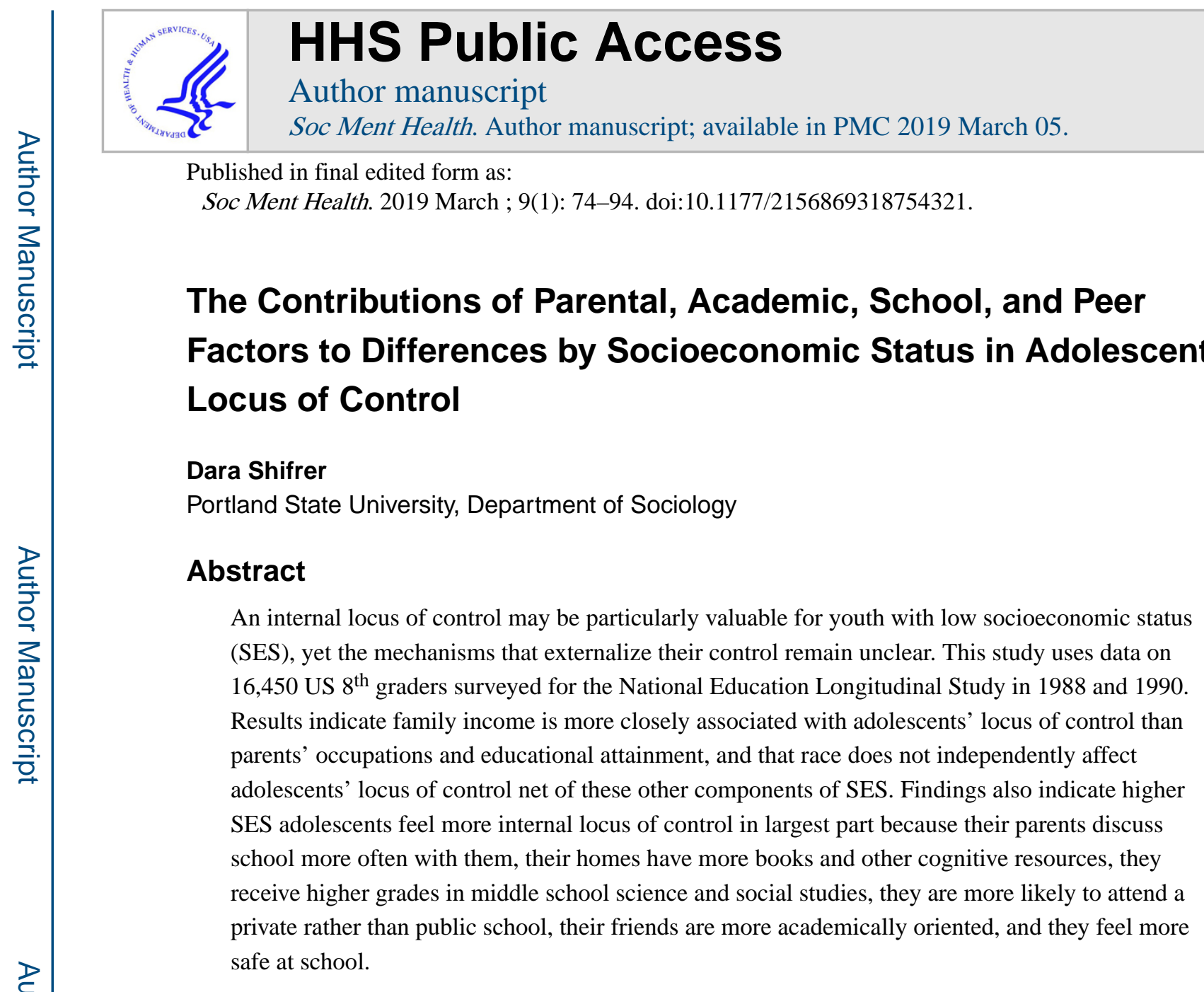

\title{
Keywords
}

Locus of Control; Child Development; Social Influence; Parenting; Peers; Socioeconomic Factors

People with more external locus of control attribute life outcomes to forces external to themselves, such as fate, destiny, or powerful others, while people with more internal control feel responsible for their successes and failures (Ross and Mirowsky 2013). An extensive previous literature documents that the more external control of youth with low socioeconomic status (SES) leads to poorer behavioral and educational outcomes (Pals et al. 2016; Suh and Suh 2006). With adolescence characterized by identity development and changes in social relations (Falci 2011), the negative effects of external locus of control in adolescence endure into adulthood (Kiviruusu et al. 2013). Decisions during adolescence reverberate through the life course, such that greater external control in disadvantaged youth may contribute to the reproduction of their disadvantage.

This study uses the social structure and personality (SSP) framework, as articulated by McLeod, Hallett and Lively (2015), to link macro to micro level processes. Applying the first principle of the SSP framework, identifying the aspects of macro-level conditions most

Send all correspondence to Dara Shifrer, Portland State University, Department of Sociology, 1721 SW Broadway Ave., Portland OR 97201, United States of America, 503.725.9262, dshifrer@pdx.edu. 
salient for individual outcomes, analyses first compare the independent contributions of four different components of SES to adolescents' locus of control: parental education, family income, race, and parents' occupation. To understand the more proximate experiences of individuals that reproduce macro structure (principle 2), this study investigates how parental, academic, school, and peer factors mediate the association between adolescent SES and locus of control. This study contributes to the sociology of mental health, social psychology, and social reproduction literatures through comprehensive measurement of SES and tangible expressions of mediation from an innovative decomposition/mediation technique.

More specifically, these investigations employ data on 16,450 US $8^{\text {th }}$ graders surveyed for the National Education Longitudinal Study (NELS) in 1988 and 1990 to focus on these research questions: 1) Which components of SES independently predict and associate most closely with adolescents' locus of control? 2) To what extent are SES differences in adolescent locus of control mediated by parental, academic, school, and peer factors? Expanding on previous studies with a similar focus but small local samples [e.g., (Duval and Silvia 2002; Frazier et al. 2011)], this study's findings are nationally representative with rich measures on a large and diverse sample of US adolescents. Although differences in control are interwoven into conceptualizations of adolescent identity (Kroger 2007), adolescent locus of control is understudied (Moilanen and Shen 2014). Although neither the locus of control construct nor processes of adolescent socialization have shifted markedly since this data was collected (Boyd 2014), the potential implications of using data from the 1990s is discussed at length in the Discussion. The only other large national dataset with a focus on adolescents' social psyches, the National Longitudinal Study of Adolescent to Adult Health (Add Health), does not include as detailed a measure of parent occupation and is only a couple of years more recent than NELS. The sections that follow integrate the literature on how parental, academic, school, and peer factors influence adolescents' social psyches with the literature on SES differences in parental, academic, school, and peer factors.

\section{LOCUS OF CONTROL AND SOCIOECONOMIC STATUS}

Julian Rotter (1954) introduced the term "locus of control" to describe differences in the degree to which people perceive themselves as having control over their own lives. People with more external control, the low end of the scale, attribute life outcomes to forces external to themselves, such as fate, destiny, or powerful others, while people with more internal control, at the high end of the scale, take responsibility for their successes and failures (Ross and Mirowsky 2013). This concept has been measured in a variety of ways [see Ross and Sastry (1999), Gould (1999), Eccles and Wigfield (2002), and Mirowsky, Ross and Van Willigen (1996)]. Gurin, Gurin and Morrison (1978) distinguished between personal control and control ideology. This study focuses on the degree to which adolescents feel they have control rather than the degree to which they feel people generally have control over their own lives. As distinguished in Thompson, Nanni and Levine (1994), this study's measure blends primary control - the control one exerts over the external environment (or action)—with secondary control—-the control one exerts internally to shape events (or acceptance). Finally, this study focuses more on present than past or future control (Frazier et al. 2011), and on adolescents' sense of control over life in general rather than in one 
specific realm (such as academics) or relative to a certain type of task (Duval and Silvia 2002).

The concept of internal control aligns closely with other indicators of mental health, such as efficacy, autonomy, agency, and instrumentalism, just as external control corresponds with fatalism (Judge et al. 2002). Some have emphasized the distinctions between each of these terms (Bonetti et al. 2001), but researchers generally agree on the substantial overlap. Locus of control is rooted in social learning theory, or is framed as a product of environment and social interactions (Miller et al. 2002). Researchers find the degree to which people perceive their lives as internally rather than externally controlled varies across culture groups with, for instance, control more internal on average in individualistic societies than in collectivist societies (Gan, Shang and Zhang 2007). Average locus of control also varies within culture groups depending on a person's social circumstances (Kraus, Piff and Keltner 2009). Although many studies have focused on the more external control of socially disadvantaged persons, the mechanisms producing such disparities remain unclear.

In correspondence with the first principle of the SSP framework, identifying the most relevant macro-social conditions for the individual outcome of interest (McLeod, Hallett and Lively 2015), this study first focuses on which components of SES relate independently to adolescents' locus of control. SES is a relative measure of an individual's macro-social position and can be conceptualized in a multitude of ways, with social class often juxtaposed against SES (Wohlfarth 1997). Bradley and Corwyn (2002) described SES as building on social class' emphasis on economic position by incorporating prestige. Krieger, Williams and Moss (1997) described social class as differences in social relationships that preceded differences in occupation, income, wealth, and education. Some disciplines emphasize differences in capital (Bradley and Corwyn 2002). Because race and SES intersect so closely in the US, and are typically considered in conjunction in research on physical and mental health outcomes (American Psychological Association 2017; Williams, Priest and Anderson 2016), this study builds on the perspective from the National Institutes of Health that race should be considered a component of SES (Oakes 2017). The more external control of socioeconomically disadvantaged persons has been demonstrated with composite measures of SES (Ahlin and Antunes 2015; Bandura et al. 2001; Falci 2011; Maqsud and Rouhani 1991; Moilanen and Shen 2014; Ross, Mirowsky and Cockerham 1983) and with measures of single SES components, such as educational attainment (Conger et al. 2009; Mirowsky and Ross 1983; Ross and Willigen 1997; Ward 2013), income (Lachman and Weaver 1998; Lever, Pinol and Uralde 2005; Ross and Mirowsky 1992), occupation (Kalil and DeLeire 2002), and race (Mabry and Kiecolt 2005; Moilanen and Shen 2014). Mirowsky, Ross and Van Willigen (1996) focused on education, income, and race, but did not consider their simultaneous contributions. This study builds on the previous research by estimating the independent contribution of a variety of SES components: parents' educational attainment, family income, parents' professional occupation status, and the adolescent's race.

This study also investigates which SES component relates most closely to adolescents' locus of control. Education had an independent effect on positive personality qualities even after holding other components of SES constant (Menaghan and Parcel 1991), and Ward (2013) found the inverse effect of parents' education on perceived constraints endured into 
adulthood. Although family income may matter more for achievement than behavioral or psychological outcomes, we generally need a clearer understanding of the mechanisms by which family income influences child development (Duncan and Magnuson 2001). Mortimer and Finch (1986) found occupational status influenced adults' social psyches more than other measures of socioeconomic status, and Whitbeck et al. (1997) showed the effect of the qualities of fathers' occupations on parenting and on children's outcomes persisted net of differences in income. Finally, researchers have argued cultural differences across racial groups may differentiate locus of control independent of racial differences in resources (Bradley et al. 2001), with Hispanics and Asians, for instance, expressing more fatalistic attitudes because of more collectivist cultures (Ross, Mirowsky and Cockerham 1983; Sastry and Ross 1998). Early studies found black youth exhibited more external control than similarly resourced white youth, with Battle and Rotter (1963) measuring SES with parental occupation and Zytkoskee, Strickland and Watson (1971) with family income.

\section{Parental, Academic, School, and Peer Factors}

The second principle of the SSP framework focuses on the proximate experiences through which macro-social structures influence the individual and through which individuals reproduce (or resist) those structures (McLeod, Hallett and Lively 2015). This section applies this principle through a discussion of parental, academic, school, and peer factors that may mechanize the relationship between SES and adolescents' locus of control. Bandura (1977) envisioned vicarious experiences and verbal persuasion as key pathways whereby youth were socialized to feel efficacy. In the case of locus of control, vicarious experiences describe opportunities youth have to see others exert control over their own lives, similar to the idea of modeling (Gecas 1989). Verbal persuasion describes direct efforts by others to convince a child of their ability to control their own lives. Bandura (1977) also predicted youths' efficacy and related qualities reflect emotional arousal, or inferences people make about their capabilities on the basis of emotional states.

Parents may first influence their child's locus of control through involvement in educational matters, a key domain for youth. Previous studies find parental support and involvement builds agency (Ross and Broh 2000), parental discussions increase self-regulation and problem-solving skills (Marin, Bohanek and Fivush 2008), and that parental involvement at school relates to increased mental health for children (Hango 2007). Building on these findings, parental discussions and parental involvement at school may internalize adolescents' locus of control by verbally persuading children of their capability and promoting culturally dominant norms related to individualism and empowerment (McNeal 1999; Perna and Titus 2005). Parents' high educational expectations may verbally persuade youth to be oriented toward the future, a correlate of internal control (Falci 2011). If not less involved (Sui-Chu and Willms 1996), lower SES parents may engage with their children differently within the home (Lareau 2003), in ways less likely to produce internal control. Lower SES parents may also be less well equipped to be effectively involved at school (Kelly 2004; Lareau 1987), and may hold slightly lower educational expectations for their children (Bradley and Corwyn 2002). The homes of socially advantaged youth may also have more books and magazines that perpetuate dominant ideology like individualism and internal control. 
Adolescents' locus of control may reflect their parents' disciplinary styles and religious influence. Some studies find parental control fosters self-discipline and internal control in children (Gecas and Schwalbe 1983), while others link it to limited autonomy and more external control (Grolnick and Ryan 1989). An authoritative approach (warmth and inductive reasoning), more common among higher SES parents, rather than an authoritarian approach (harsher, punishment based) may be the important distinction whereby parental control allows children to vicariously experience empowerment (Falci 2011; Lareau 2003). Religious experiences are typically organized by parents (Stokes and Regnerus 2009). Although findings are mixed (Bartkowski, Xu and Levin 2008; Ellison 1993), religiosity, particularly within more fundamentalist denominations, has been linked to more external control, with the individual verbally persuaded that causality lies with God rather than the self (Schieman, Nguyen and Elliott 2003). Fundamentalist religiosity is more prevalent among low SES individuals (Schieman et al. 2006).

For instance, whereas the homes of socially advantaged youth may provide information and tools which materially enable successful navigation of school and the wider world (Gecas and Schwalbe 1983), the uncertainty of living in a home with limited resources for managing the adversities of daily life may lead to states of emotional arousal that convinces children they cannot control their own life (Mittal and Griskevicius 2014). Although an imperfect measure (Jaffee et al. 2003), the presence of both biological parents in the home may also represent a higher degree of family stability (Manning, Smock and Majumdar 2004). Low SES adolescents live in homes with fewer material resources, and are less likely to live with both biological parents (Martin 2006).

Prior academic experiences and school structure may shape adolescents' locus of control. Academics is a central domain for youth, such that the vicarious experience of experiencing success at school (e.g., high course grades, speaking the dominant language), experiences more common among higher SES youth (Gándara 1995; Reardon 2011), may internalize control more broadly (Gándara 1995; Karlson 2015; Madon, Jussim and Eccles 1997). Schools with more deep interpersonal connections and opportunities for mentoring (e.g., more teachers per students) may internalize adolescents' control through both verbal persuasion and emotional arousal (Coleman 1961; Coleman 1988; Stewart 2008).

Adolescents' locus of control may be externalized in schools with authoritarian rather than authoritative climates (Gregoire and Algina 2000), where discipline is emphasized or grade promotion controlled. Schools may internalize students' control by providing vicarious experiences for personal development (e.g., job training), but externalize control through structural barriers to such opportunities (e.g., minimum grade point average (GPA)) (Garcia 2015; Gastic 2010). The schools of lower SES youth tend to have more controlling climates (Gastic 2010) and offer fewer opportunities for personal development (Cohen et al. 2007).

Finally, peers and friends may also provide vicarious experiences, verbal persuasion, and emotional arousal that differentiate adolescents' locus of control in class-specific ways. Youth in the US tend to attend schools with similarly resourced peers (Orfield et al. 2014), such that high SES adolescents may be more likely to be surrounded by peers also socialized in norms and values related to individual empowerment and ambition (Coleman 1990; Cookson and Persell 1985). In contrast, the schools of socially disadvantaged youth, 
characterized by lower average achievement levels and more externalizing behaviors (Fletcher 2015), may be pervaded by a general sense of external control (Gecas and Schwalbe 1983). Adolescents who experience more classroom disruptions may vicariously experience their teachers' seeming inability to control the classroom, just as their struggles to learn in classrooms and halls with more negative peer behaviors may arouse feelings of externalized control. Youth who are threatened or bullied by peers likely feel less control (Mirowsky and Ross 1983). In all, low SES youth tend to experience more negative peer interactions (Bradley and Corwyn 2002).

\section{OVERVIEW OF CURRENT STUDY}

This study identifies which components of SES independently predict and associate most closely with adolescents' locus of control, and then investigates the extent to which these associations are mediated by parental, academic, school, and peer factors. With locus of control a quality that parallels persistent characteristics of youths' social contexts (Crosnoe and Huston 2007), this study builds on the possibility that measures of SES, parents, schools, and peers from a single point in time are evocative of general trends in the adolescents' life. While these factors vary over the years, important differences that distinguish the lives of lower and upper SES children have some constancy over time (Lareau 2003). Similarly, an individual's family income and even parental occupation or educational attainment may vary over time (Duncan and Magnuson 2001) but true social mobility is rare across generations, let alone the span of one person's childhood years (Neckerman and Torche 2007). With a primary interest in long-term correlates of locus of control, this study does not examine change in control between the first two waves of data collection-exploratory analyses (detailed in next section) demonstrated changes were small, similar to evidence that adjustment profiles are fairly consistent across the teen years (Matjasko, Grunden and Ernst 2007).

\section{DATA AND METHODS}

The National Center for Education Statistics (NCES) used a two-stage probability design to select a nationally representative sample of $8^{\text {th }}$ grade schools and students in the US in 1988 for NELS (around 24,600 students in 815 public and 237 private schools) (Curtin et al. 2002). (NCES requires unweighted frequencies be rounded to nearest 10.) This study uses data from the base year parent and school administrator surveys, linked administrative data describing schools, and data from the 1990 follow-up survey (when most sampled adolescents were in the $10^{\text {th }}$ grade). This first follow-up attempted to include drop-outs, and added students who did not participate in the base year to maintain the sample's national representativeness (Curtin et al. 2002). After excluding 1,620 students missing on the dependent variable and 1,560 missing a base year school ID (required for multilevel modeling), this study's analytic sample includes approximately 16,450 adolescents in 1,500 high schools. The base year to first follow up panel weight is used in all analyses to account for survey design. Table 1 provides descriptive statistics on all variables used in analyses. Missing values on independent variables were addressed with multiple imputation by the MICE system of chained equations (White, Royston and Wood 2011). Across the variables used in this study, $3.0 \%$ of cases were missing on average. Highest rates of missingness were 
evident on adolescents' reports of whether they attend remedial math (15.7\%) and remedial English (8.7\%), their parents' educational expectations for them (10.2\%), and participation in religious activities (from $6.5 \%$ to $9.8 \%$ ), as well as parents' reports of family income (9.8\%). Missingness is often high on income variables (Tourangeau and Yan 2007), and may be high on these other variables because of similar issues of sensitivity.

\section{Dependent Variable: $10^{\text {th }}$ Grade Locus of Control}

NCES constructed the locus of control composite measure from six items on the $10^{\text {th }}$ grade student survey to which adolescents reported the degree to which they agreed (1=Strongly agree to $4=$ Strongly disagree): "I don't have enough control over the direction my life is taking," "In my life, good luck is more important than hard work for success," "Every time I try to get ahead, something or somebody stops me," "My plans hardly ever work out, so planning only makes me unhappy," "When I make plans, I am almost certain I can make them work," and "Chance and luck are very important for what happens in my life" [alpha=0.71 (Ingels et al. 1992)]. The survey items on locus of control were based on a short form of Rotter's (1966) scale (Wolfle and List 2004). NCES reverse coded the $5^{\text {th }}$ item, and standardized each item using the first follow-up student survey weight. For this study, the entire scale was standardized so that zero represents the average locus of control among the nation's $10^{\text {th }}$ graders. Lower values on the scale described a more external locus of control, while higher values described a more internal locus of control. Confirming research on the stability of locus of control over the life course (Wolfle and List 2004), adolescents' average locus of control from NELS' first and second waves of data collection varied minimally (respectively, mean of 0.00 and standard deviation of 0.62 , and mean of 0.01 and standard deviation of 0.63$)$.

\section{Predictors of Interest: Socioeconomic Status Components}

NCES only measured SES during the base year of data collection ( $8^{\text {th }}$ grade), which facilitated the longitudinal prediction of $10^{\text {th }}$ grade locus of control. Adolescent race was categorized as 'White, Not Hispanic,' 'Black, Not Hispanic,' 'Hispanic,' or 'Other' (combines 'Asian, Pacific Islander' and 'American Indian, Alaskan'). Parents reported family income in the base year (ranges from $1=$ ' $\$ 0$ ' to $15=$ ‘ $\$ 200,000$ or more'). NCES constructed a composite of parents' educational attainment using parents' and adolescents' base year reports. I transformed this composite into an ordinal variable indicating whether at least one of each adolescent's parents completed high school or less, some college, or a Bachelor's degree or higher.

Parents reported the occupations of adolescents' father/male guardian and mother/female guardian. Although NCES used 'parents or guardians' in each survey question, this manuscript uses 'parents' for ease of reference. This study classifies the occupation of each parent as professional ('Mgr/Administrator,' 'Sales,' 'School Teacher,' 'Professional 1,' 'Professional 2,' 'Proprietor/Owner,' and 'Technical') or not professional ('Clerical,' 'Craftsperson,' 'Don't Know,' 'Farm Manager,' 'Farmer,' 'Homemaker,' 'Laborer,' 'Military,' 'Never Worked,' 'Operative,' 'Protective Service,' and 'Service'). I combined the variables describing each parent/guardian into a single dichotomous variable indicating whether at least one parent was in a professional occupation. In this way, adolescents in 
single-parent homes are included in the measure's categories without duplicating information from the family structure variable, and adolescents with a homemaking mother but professional father (characteristic of higher SES families) are classified as having a professional parent. Never working was too rare among both fathers and mothers, and homemaking too rare among fathers, to analytically separate. Adolescent control was not independently affected by a homemaking mother; moreover, considering homemaking mothers as a distinct category did not improve the fit of the model.

Because NELS' occupational categories do not clearly indicate status and NCES did not provide additional occupational information or income data specific to each parent, I conducted several sensitivity analyses to determine the reliability of the construction of the parental occupation variable. Parents in professional occupations were more likely than parents in non-professional occupations to have completed at least some college, and to have an average family income above $\$ 35,000 /$ year (Online Table 1 ). Online Table 2 details the prevalence of occupational categories less clearly linked to a professional status ('Homemaker,' 'Never worked,' 'Don't know,' and missing). The final constructed parental occupation measure classified an adolescent with one professional parent and one unclear parent as having parent(s) in a professional occupation. Online Table 3 shows the average qualities of adolescents classified as having professional parent(s) were similar regardless of the clarity of their parents' occupational categories, just as the average qualities of adolescents classified as not having professional parent(s) were similar regardless of the clarity of their parents' occupational categories. In a fourth set of sensitivity analyses, I reestimated main analyses excluding adolescents $(n=4,930)$ if one or both of their parents' occupational categories was unclear. The similarity between findings from these analyses and main results provide additional confidence in the study's operationalization of parents' occupations.

\section{Potential Mediators: Parental, Academic, School, and Peer Factors}

This study focuses on parental, academic, school, and peer factors as potential mediators in the association between SES and adolescent locus of control. Extensive exploratory analyses determined which measures were suitable (correlated with both SES and locus of control), and which measured a similar latent factor and could be combined into a scale.

$8^{\text {th }}$ Grade Parental Influences-Parental influences are first measured with adolescents' reports of whether they lived with both biological parents (this was the only measure of parental influence only available in the first follow-up data). An index of cognitive household resources sums adolescents' reports on which of these items were present in their household: daily newspaper, regularly received magazine, encyclopedia, atlas, dictionary, typewriter, computer, more than 50 books, and pocket calculator. The material household resources index sums which of these items were present in the household: electric dishwasher, clothes dryer, washing machine, microwave oven, and VCR. Dichotomous measures indicate whether the adolescent attended a religious education class, or participated in a religious organization or youth group. 
The frequency of parental involvement in educational matters is measured by adolescents' reports of discussions about school issues with their parents, parental involvement at school, and their parents' educational expectations for them. Discussions with parents are measured by a scale summing the number of times ( $3=3$ or more times, $2=$ once or twice, $1=$ Not at all) adolescents reported discussing the following with their parents since the beginning of the school year: selecting courses or programs at school, school activities or events, and things studied in class (alpha $=0.61$ ). Parental involvement is measured by a scale summing adolescents' indications ( $1=$ Yes, $0=\mathrm{No}$ ) of whether either of their parents had done the following since the beginning of the school year: attended a school meeting; phoned or spoken to a teacher or counselor; visited a class; attended a school event such as a play, concert, gym exhibit, sports competition, honors ceremony, or science fair. I average ordinal measures of parents' educational expectations (alpha=0.84; $1=$ Less than high school, $2=$ Graduate high school, $3=$ Vocational schooling after high school, 4=Attend college, $5=$ Graduate from college, $6=$ Higher school after college). Differences in parental disciplinary control are measured through indicators of how often $(0=$ Never to $3=$ Often) parents checked on adolescents' homework, required chores around the home, and limited adolescents' time watching TV or going out with friends. Unfortunately, NELS' questions related to parental discipline were not designed to distinguish between authoritative and authoritarian parenting.

Prior Academic Experiences-In the baseline year ( $8^{\text {th }}$ grade), adolescents reported whether English was their native language; whether they had ever been retained a grade level; whether they attend remedial English/math at least once a week; and their average grades in English, math, science, and social studies from grade 6 until grade 8 (recoded so that 4=Mostly As, 3=Mostly Bs, 2=Mostly Cs, $1=$ Mostly Ds, $0=$ Mostly below Ds).

$8^{\text {th }}$ Grade School Structure-To capture aspects of school structure that may facilitate or inhibit interpersonal relationships and mentoring, I use school administrator reports of student enrollment, teacher to student ratio, and proportion teachers with a graduate degree. Opportunities for personal development are measured by administrator reports on the number of extracurriculars available to $8^{\text {th }}$ graders and the proportion of students in job training. To capture the degree to which the school maintains a controlling climate, administrator reports describe whether the school has formal admission procedures, emphasizes discipline $(0=$ Not at all accurate, $\ldots 5=$ Very much accurate), requires a minimum GPA to participate in activities, and the number of competency tests students must pass for grade promotion.

$8^{\text {th }}$ Grade Peer Influences-Peer influences are first captured by administrative measures of whether the school is private and the proportion of students at the school who are eligible for the free lunch program or racial minorities. While school type could be considered a structural measure, the better outcomes of students in private schools are explained to a much larger extent by differences in students' backgrounds than differences in schools (Carbonaro and Covay 2010; Coleman, Hoffer and Kilgore 1982). Moreover, differences across homes explain much more of the variation in achievement than differences in schools (Gamoran and Long 2006; Haertel 2013; Hill 2016), and, among the 
school factors that matter, peers matter more than school structure or average teacher qualities (Coleman 1990). These facts are likely to be relevant for students' mental health as well, because previous research documents how schools serving higher proportions of poor youth tend to have peer climates marked by more external average locus of control, heightened levels of academic disengagement, and more externalizing behaviors (Coleman 1990; Noguera 2008). Moreover, some find school racial composition exerts an independent effect on student outcomes independent of student body poverty level, partially because of differences in peer climate (Farkas, Lleras and Maczuga 2002; Hanushek, Kain and Rivkin 2009). The academic orientation of adolescents' friends is measured with a scale summing adolescents' reports on the degree to which each of the following were important to their friends ( $0=$ Not important to $2=$ Very important): attending classes regularly, studying, getting good grades, finishing high school (alpha $=0.85$ ). To understand differences in negative peer behaviors, I use base year reports on the degree to which adolescents agreed other students often disrupted class or learning ( $0=$ Strongly disagree to $3=$ Strongly agree). Similarly, a scale sums school administrator reports on the degree to which student tardiness, absenteeism, class cutting, physical conflicts, theft, vandalism, alcohol and drug use, weapons, and abuse of teachers are problems at the school ( $0=$ Not a problem to $3=$ Serious). Adolescents' negative interactions with peers are measured through their base year reports on how often someone threatened to hurt them at school or something of theirs was stolen $(0=$ Never, $1=$ Once or twice, $2=$ More than twice $)$, and their agreement that they do not feel safe at their school $(0=$ Strongly disagree to $3=$ Strongly agree $)$.

\section{Analytic Plan}

To understand independent effects, a multilevel fixed-intercept linear regression model predicts adolescents' locus of control with the four SES components. Fixed-intercept models account for the clustered nature of the data and focus on within-school differences (Halaby 2004). F-ratios from Wald tests post-estimated from this model show which SES components associate most closely with adolescents' locus of control. A sensitivity analysis focused on the reliability of the parental occupation variable re-estimates this model with the alternate coding of the variable. Coefficients from both models are available in Online Table 4. Next, a decomposition technique developed by Kohler, Karlson and Holm (2011) shows the degree to which the effect of each SES component on adolescents' locus of control is mediated by differences in parental, academic, school, and peer factors. Separate decomposition analyses respectively focus on family income, parental education, and parental occupation as predictors of interest, with the other SES components included as controls_-adolescents' race is only used as a control in each decomposition analysis because results indicate race does not independently associate with locus of control. A fourth decomposition analysis uses the alternate measure of parental occupation as a sensitivity analysis. This technique, based in regression modeling, produces percentages representing the mediational contribution of each parental, academic, school, and peer factors, controlling for other potential mediators and SES components. The tangible estimates (percentages rather than regression coefficients) produced by this method answer the increasing call for a shift in focus from statistical to substantive significance (Healy and Moody 2014). Standard errors are adjusted to account for the clustered nature of the data. Online Table 5 shows bivariate relationships between adolescents' SES, locus of control, and potential mediators 
- to facilitate interpretation, these results are also summarized more briefly in the first two columns of the table focused on mediation results (Table 2).

\section{RESULTS}

\section{Association between Different Components of SES and Adolescent Locus of Control}

In addition to descriptive statistics, Table 1 provides F-ratios from a multilevel linear regression model predicting adolescents' locus of control with all SES components included (full models in Online Table 4). Family income, with the largest F-ratio, is more closely related to adolescents' locus of control than any other SES component. Parents' educational attainment is more closely associated to adolescents' locus of control than parents' occupational status. Because race has the lowest F-ratio and race differences are not statistically significant (Online Table 4), mediation analyses focus on the three SES components independently associated with adolescents' locus of control, while only controlling for race.

\section{Potential Mediators: Parental, Academic, School, and Peer Factors}

Table 2 shows how parental, academic, school, and peer factors mediate the association between adolescents' SES and locus of control. Each model focuses on one SES component and controls for the other SES components. The first column in Table 2 shows the direction of the baseline association (i.e., no controls) of higher SES with each mediator, and then the direction of the baseline association of a positive or higher value on the mediator with adolescent locus of control (more detailed results in Online Table 5). In general, higher SES adolescents are more likely to experience the parental influences measured in this study, are more likely to experience academic successes, and less likely to experience academic failures. Higher SES adolescents are less likely to attend schools characterized by most of this study's structural measures, except that their schools have higher proportions of teachers with graduate degrees, and are more likely to have formal admission procedures and emphasize discipline (counter to what the literature would predict). Higher SES adolescents are less likely to experience most of the peer influences measured in this study with the exceptions that they are more likely to attend a private school and to have friends who are more academically oriented. In every case, the parental, academic, school, and peer factors more common across higher SES adolescents relate to more internal control (at the baseline), whereas those that are less common relate to more external control.

The percentages in Table 2 represent the extent to which each measure explains the estimated effect of the SES component on adolescents' locus of control, net of other SES components and other potential mediators. For example, the top left cell shows that $2.0 \%$ of the total effect of family income on adolescents' locus of control is mediated by these adolescents' increased likelihood of living with both their biological father and mother. Negative indirect effects indicate the measure did not contribute to explaining the relationship between the SES component and adolescents' locus of control. The contribution of each group of mediators is summed at the end of each section. In all, the association between SES and adolescent locus of control is mediated to the least extent by school structure, which is consistent with the long line of research that finds differences across 
schools and teachers explain very little of the variation in students' outcomes (usually academic) relative to differences across homes (Hill 2016). The estimated effect of family income on adolescents' locus of control is mediated to the greatest extent by this study's measures of parents, whereas prior academic experiences and peers are respectively the largest mediators for the estimated effects of parents' educational attainment and parents' professional occupations on adolescents' locus of control. Nonetheless, parents, academic experiences, and peers each contribute a great deal to the associations between each SES component and adolescent locus of control. Confidence in the reliability of the main parental occupation measure is increased by the similarity in results between the models relying on the main and alternate versions of the parent occupation measure, with the latter excluding adolescents whose parents' occupational categories did not clearly indicate a professional or a non-professional status.

The 'Rank' columns in Table 2 identify the top five mediators for each SES component. Parental discussions about school contribute substantially to the more internal control of adolescents with higher SES across all SES components. In one example, $13.8 \%$ of the total effect of parents' educational attainment on adolescents' locus of control is mechanized through educated parents' higher likelihood of engaging their children in discussions about school. SES differences in parental discussions similarly comprise $10.8 \%$ and $9.7 \%$ of the respective total effects of family income and parents' professional occupation on adolescents' locus of control. SES differences in the number of household cognitive resources are also an important contributor, comprising $11.6 \%$ and $9.3 \%$ of the respective total effects of family income and parents' highest level of education on adolescents' locus of control. Supplementary analyses demonstrate that certain cognitive resources-having a place to study, magazines, encyclopedias, computers, and many books-are key contributors. Students' average GPA in science and social studies are the most important aspect of prior academic experiences for the association between SES and adolescents' locus of control, contributing around $8 \%$ each to the effect of family income, $14 \%$ the effect of parents' education, and 7\% to the effect of parents' occupation. It is possible skills in reading/English, and math in particular, are perceived as inherent traits (Epstein, Mendick and Moreau 2010), making students more likely to attribute high grades in science and social studies to their own efforts and subsequently more broadly increasing their sense of control. Feeling safe at school is an important peer influence, comprising $8.4 \%$ and $12.3 \%$ of the respective positive effects of parents' educational attainment and a professionally occupied parent on adolescents' locus of control. $4.9 \%$ of the positive total effect of having parent(s) in a professional occupation is due to these adolescents' more academically oriented friends. Finally, wealthier adolescents feel more internal control in part because they are more likely to attend a private rather than a public school.

\section{DISCUSSION}

The outcomes of socioeconomically disadvantaged youth may particularly benefit from an internal locus of control yet the previous literature documents these youth are the least likely to feel they can control their lives. The mechanisms producing SES disparities in locus of control were largely unexplored. This study used nationally representative data to show race does not independently relate to adolescent locus of control. Although family income is 
most closely associated with adolescents' locus of control, parents' occupations and educational attainment contribute independently as well. Parent, academic, and peer factors each contributed substantially to the association between SES and adolescents' locus of control, whereas school factors did not. Based on the measures available in this data, findings indicate higher SES adolescents feel more internal locus of control in largest part because their parents discuss school more often with them, their homes have more books and other cognitive resources, they receive higher grades in middle school science and social studies, they are more likely to attend a private rather than public school, their friends are more academically oriented, and they feel safer at school.

Findings generally support the role of socialization (e.g., verbal persuasion, vicarious experiences) in SES differences in youths' locus of control, with parents' interactions with their children an important contributor among those measured. Moilanen and Shen (2014) similarly found supportive-involved parenting key for internalizing adolescents' control. Ahlin and Antunes (2015) found parents influence adolescent locus of control more than peers but did not consider parents and peers as mediators between social SES and locus of control; their data was also Chicago-specific rather than national. Although socially disadvantaged parents may struggle to engage with their children in ways that internalize control (Duncan and Magnuson 2001), there is some evidence that policy interventions aimed at altering parents' interactions with their children can be successful, such as The Baby College in Harlem Children's Zone (Tough 2008) and READY4K! in San Francisco (York and Loeb 2014). The current study's findings related to peer influences coincide with research on the disorder and academic disinvestment that characterize schools serving poorer students (i.e., negative emotional arousal) (Farkas, Lleras and Maczuga 2002). With these marked distinctions in the contexts and socialization of lower SES adolescents, disparities in internal locus of control may be a factor in social reproduction.

Findings also support the possibility that real deficiencies in resources externalize socially disadvantaged adolescents' control, possibly through the arousal of negative emotions. Family income, potentially the nearest approximate for tangible resources and power, is more closely associated with adolescents' locus of control than other SES components. Additionally, the influence of school type on adolescents' locus of control, after accounting for differences in peer behaviors, may represent cross-school differences in resources that actually enable students to have control over their futures. Finally, in addition to coinciding with findings from previous studies that document the mutually constitutive relationship between academic success and internal control (Cappella and Weinstein 2001), the association between low SES and lower levels of academic achievement is extensively documented (Reardon 2011), and may represent another aspect of lower SES youths' lives that they materially cannot control.

Future research might focus on whether the benefits of internal locus of control are uniform across diverse youth. If low SES youth face objectively more barriers than higher SES youth, their perceptions that their life is not entirely within their own control is an accurate perception. Some studies theorize individualistic cultures may lead lower status persons to attribute failures to themselves despite seemingly clear structural roots (Sechrist, Swim and Stangor 2004). Attributing failures to powerful others may provide psychological relief 
(Ruggiero and Taylor 1997), particularly for people who truly lack control (Glavin and Schieman 2014). In a relevant example, the negative psychological effects of job loss were exacerbated for persons with more internal control (Heidemeier and Goritz 2013). A failure of significant others, such as educators and parents, to recognize material differences in control may amount to placing the burden of structural problems on the shoulders of the oppressed (Marks 1998). It is possible lower SES parents intentionally teach their children to be cognizant of structural barriers as a means of empowerment, a situating on the middle of the locus of control scale Marks (1998) described as ideal. Positively reframing appraisals of current stressors while persisting with a future-focus uniquely benefitted the physiology of adults who grew up in low SES households (Chen et al. 2012). Chen and Miller (2012) similarly found persons whose health was not negatively impacted by their low SES had been taught to "shift-and-persist," that is, to accept the stresses of their lives and adapt to them with persistence.

Certain limitations of this study merit mention. This study's findings may be affected by measurement issues. For instance, the scale available in this dataset may not achieve the balance recommended by Mirowsky and Ross (1991), i.e., including statements about good and bad outcomes as well as internal and external statements. Adolescents' $10^{\text {th }}$ grade reports on their personal control may have been influenced by the similar question on their $8^{\text {th }}$ grade survey (Warren and Halpern-Manners 2012). Family income does not capture differences in wealth (Oliver and Shapiro 2006 [1995]), and these analyses should be replicated once data with more nuanced measures of SES are available. Although Stokes and Regnerus (2009) describe religion and family as "tightly linked institutions," and used national data to show that only around $10 \%$ of adolescents rated religion as much less important than their parent rated it, it is possible this study's measures of religious participation capture peer influence or personal initiative rather than parent influence. In other limitations, this study's measures did not explain one hundred percent of the effect of each SES component, suggesting the implication of factors not measured in this data, perhaps even shared genetic traits rather than social influences (Brown 2002). Previous research suggests personalities are better explained by environmental than genetic differences (Roberts, Wood and Smith 2005), particularly after early childhood (Briley and Tucker-Drob 2014), and, ultimately, Freese and Powell (2003) argue it is very difficult to disentangle the intertwining influences of environment and genes.

Although this study is longitudinal, temporal order can still be difficult to establish without an experimental design. For instance, parents' social psychological qualities influence family SES, such that the seeming influence of SES on adolescents' social psyches may actually reflect the direct transmission of social psychological qualities from parent to child. Parental interactions may be the result rather than the cause of their child's choices and behaviors [see Kerr, Stattin and Burk (2010) or Gecas and Seff (1990)]. Adolescents may surround themselves with peers who share their perspectives rather than being influenced by peers' perspectives (Vitaro et al. 1997). In contrast to studies focused on adults (Bradley and Corwyn 2002), this study's focus on adolescents makes it unlikely their SES is the result, rather than the cause, of their social psyches. Nonetheless, this study identifies many associations that are important targets for future research and policy. 
Finally, the current applicability of this study is limited by its focus on adolescents in high school in the early 1990s. It is unlikely that NELS' measure of locus of control is outdated, as differences in locus of control measurements are more conceptually than temporally driven (Bursik and Martin 2006). Nonetheless, different measures of control may yield different results (Ward 2013). Similarly, with desegregation efforts stalled and even reversed, disadvantaged youth are still clustered in schools with other disadvantaged youth (Orfield 2014). Alternatively, it is possible SES disparities in internal control are more stark today, with inequality in the US increasing (Western and Rosenfeld 2011). Contemporary patterns in these processes may also differ because of shifts in parenting norms and social media use. Parents today, particularly middle class mothers (Romagnoli and Wall 2012), are increasingly likely to engage in 'intensive parenting' or 'helicopter parenting.' Intensive parenting describes parents' attempts to manage and control risk factors in order to enable optimal outcomes for offspring (Shirani, Henwood and Coltart 2012), with more resilient children a specific goal (Hoffman 2010). Lareau (2003) found that middle class parents' concerted cultivation, perhaps akin to intensive parenting, produced children willing to challenge authority. In these ways, future studies may find parenting contributes even more substantially to the more internal control of higher SES youth. Alternatively, critics argue intensive parenting produces 'helpless' children (Barron 2016), such that we might expect fewer disparities by SES in internal control among contemporary youth. Focus on increased internet and social media use coincides with arguments that the psychological struggles of adolescence have increased over time, with unceasing demands for public-ready presentations of self, the encroachment of the peer group into the home, and increased risk of cyberbullying or sexting. Most conclude these concerns are overstated (Gross 2004; Katz and Rice 2002; Valkenburg and Peter 2009), with major adolescent themes remaining constant despite these social changes (Boyd 2014). Although excessive internet or social media use relates to poorer mental health (Livingstone 2008; Subrahmanyam et al. 2001), studies find the average adolescent user experiences increased social connections and access to information (Bushman and Huesmann 2006; O'Keeffe, Clarke-Pearson and Council on Communications and Media 2011). This suggests the gap in internal control may be more marked among contemporary youth than the youth in this study, as higher SES youth tend to have more access to these technologies (Schradie 2012; Subrahmanyam et al. 2001). Ultimately, these temporal changes in our modes of social interaction suggest the importance of building on the findings of this study as new data becomes available.

Despite these limitations, this study extends previous explorations of the association between SES and locus of control by examining the simultaneous contribution of several dimensions of SES and incorporating consideration of the characteristics of parents, schools, and peers that produce these associations. Future research might consider possibilities suggested by previous research: heterogeneity in the personal control of low SES youth (Carter 2006), and gender, SES, or race variation in the social processes that shape locus of control (Bruce and Thornton 2004). It is unclear, for instance, whether parental involvement at school is more beneficial for children from higher SES (McNeal 1999; McNeal 2001) or lower SES (Domina 2005) families. Studies contrasting individualistic and collectivist societies found internal control is most useful in cultures that explicitly value this trait (the 
former) (Sastry and Ross 1998), an idea that may extend to contextual differences within the US (Shifrer and Sutton 2014).

\section{Supplementary Material}

Refer to Web version on PubMed Central for supplementary material.

\section{Acknowledgments}

This research was supported by grants, 5 R24 HD042849 and 5 T32 HD007081, awarded to the Population Research Center at The University of Texas at Austin by the Eunice Kennedy Shriver National Institute of Health and Child Development.

\section{References}

Ahlin, Eileen M; Antunes, Maria Joao Lobo. 2015; Locus of Control Orientation: Parents, Peers, and Place. Journal of Youth and Adolescence. 44(9):1803-18. [PubMed: 25617000]

American Psychological Association. Ethnic and Racial Minorities \& Socioeconomic Status. 2017. Retrieved November 2017 (http://www.apa.org/pi/ses/resources/publications/minorities.aspx)

Bandura, Albert. 1977; Self-Efficacy: Toward a Unifying Theory of Behavioral Change. Psychological Review. 84(2):191-215. [PubMed: 847061]

Bandura, Albert; Barbaranelli, Claudio; Caprara, Gian Vittorio; Pastorelli, Concetta. 2001; SelfEfficacy Beliefs as Shapers of Children's Aspirations and Career Trajectories. Child Development. 72(1):187-206. [PubMed: 11280478]

Barron, Carrie. Hands-Off Parenting for Resilient, Resourceful Children. 2016. Retrieved September 2017 (https://www.psychologytoday.com/blog/the-creativity-cure/201604/hands-parenting-resilientresourceful-children)

Bartkowski, John P; Xu, Xiaohe; Levin, Martin L. 2008; Religion and Child Development: Evidence from the Early Childhood Longitudinal Study. Social Science Research. 37(1):18-36.

Battle, Esther S; Rotter, Julian B. 1963; Children's Feelings of Personal Control as Related to Social Class and Ethnic Group. Journal of Personality. 31(4):482-90. [PubMed: 14086840]

Bonetti, Debbie; Johnston, Marie; Rodriguez-Marin, Jesus; Pastor, Mariangeles; Martin-Aragon, Maite; Doherty, Eva; Sheehan, Katherine. 2001; A Factor Analysis of Three Measures and an Examination of Their Relation to Activity Level and Mood in a Student and Cross-Cultural Patient Sample. Psychology and Health. 16(6):655-74.

Boyd, Danah. It's Complicated: The Social Lives of Networked Teens. New Haven, CT: Yale University Press; 2014.

Bradley, Robert H; Corwyn, Robert F. 2002; Socioeconomic Status and Child Development. Annual Review of Psychology. 53:371-99.

Bradley, Robert H; Corwyn, Robert F; McAdoo, Harriette Pipes; Coll, Cynthia Garcia. 2001; The Home Environments of Children in the United States Part I: Variations by Age, Ethnicity, and Poverty Status. Child Development. 72(6):1844-67. [PubMed: 11768149]

Briley, Daniel A, Tucker-Drob, Elliot M. Psychological Bulletin. Advance online publication; 2014. Genetic and Environmental Continuity in Personality Development: A Meta-Analysis.

Brown, George W. 2002; Social Roles, Context and Evolution in the Origins of Depression. Journal of Health and Social Behavior. 43(3):255-76. [PubMed: 12467252]

Bruce, Marino A; Thornton, Michael C. 2004; It's My World? Exploring Black and White Perceptions of Personal Control. Sociological Quarterly. 45(3):597-612.

Bursik, Krisanne; Martin, Timothy A. 2006; Ego Development and Adolescent Academic Achievement. Journal of Research on Adolescence. 16(1):1-18.

Bushman, Brad J; Rowell Huesmann, L. 2006; Short-Term and Long-Term Effects of Violent Media on Aggression in Children and Adults. Archives of Pediatrics and Adolescent Medicine. 160(4): 348-52. [PubMed: 16585478] 
Cappella, Elise; Weinstein, Rhona S. 2001; Turning Around Reading Achievement: Predictors of High School Students' Academic Resilience. Journal of Educational Psychology. 93(4):758-71.

Carbonaro, William; Covay, Elizabeth. 2010; School Sector and Student Achievement in the Era of Standards Based Reforms. Sociology of Education. 83(2):160-82.

Carter, Prudence L. 2006; Straddling Boundaries: Identity, Culture, and School. Sociology of Education. 79(4):304-28.

Chen, Edith; Miller, Gregory E. 2012; "Shift-and-Persist" Strategies: Why Being Low in Socioeconomic Status isn't Always Bad for Health. Perspectives on Psychological Science. 7(2): 135-58. [PubMed: 23144651]

Chen, Edith; Miller, Gregory E; Lachman, Margie E; Gruenewald, Tara L; Seeman, Teresa E. 2012; Protective Factors for Adults from Low Childhood Socioeconomic Circumstances: The Benefits of Shift-and-Persist for Allostatic Load. Psychosomatic Medicine. 74(2):178-86. [PubMed: 22286848]

Cohen, Deborah A; Taylor, Stephanie L; Zonta, Michela; Vestal, Katherine D; Schuster, Mark A. 2007; Availability of High School Extracurricular Sports Programs and High Risk Behaviors. Journal of School Health. 77(2):80-86. [PubMed: 17222159]

Coleman, James; Hoffer, Thomas; Kilgore, Sally. 1982; Cognitive Outcomes in Public and Private Schools. Sociology of Education. 55(2):65-76.

Coleman, James S. The Adolescent Society: The Social Life of Teenagers and its Impact on Education. New York, NY: Free Press of Glencoe; 1961.

Coleman, James S. 1988; Social Capital in the Creation of Human Capital. The American Journal of Sociology. 94:S95-S120.

Coleman, James S. Equality and Achievement in Education. Boulder, CO: Westview Press; 1990.

Conger, Katherine Jewsbury; Williams, Shannon Tierney; Little, Wendy M; Masyn, Katherine E; Shebloski, Barbara. 2009; Development of Mastery during Adolescence: The Role of Family Problem-Solving. Journal of Health and Social Behavior. 50(1):99-114. [PubMed: 19413137]

Cookson, Peter W, Persell, Caroline H. Preparing for Power: America's Elite Boarding Schools. New York, NY: Basic Books; 1985.

Crosnoe, Robert; Huston, Aletha C. 2007; Socioeconomic Status, Schooling, and the Developmental Trajectories of Adolescents. Developmental Psychology. 43(5):1097-110. [PubMed: 17723038]

Curtin, Thomas R, Ingels, Steven J, Wu, Shiying; Heuer, Ruth. National Education Longitudinal Study of 1988: Base-Year to Fourth Follow-up Data File User's Manual (NCES 2002-323). Washington, DC: U.S. Department of Education, National Center for Education Statistics; 2002.

Domina, Thurston. 2005; Leveling the Home Advantage: Assessing the Effectiveness of Parental Involvement in Elementary School. Sociology of Education. 78(3):233-49.

Duncan, Greg J, Katherine, Magnuson. Off with Hollingshead: Socioeconomic Resources, Parenting, and Child Development. In: Bornstein, Marc H, Bradley, Robert H, editors. Socioeconomic Status, Parenting, and Child Development. Mahwah, NJ: Lawrence Erlbaum; 2001.

Duval, Thomas Shelley; Silvia, Paul J. 2002; Self-Awareness, Probability of Improvement, and the Self-Serving Bias. Journal of Personality and Social Psychology. 82(1):49-61. [PubMed: 11811633]

Eccles, Jacquelynne S; Wigfield, Allan. 2002; Motivational Beliefs, Values, and Goals. Annual Review of Psychology. 53:109-32.

Ellison, Christopher G. 1993; Religious Involvement and Self-Perception Among Black Americans. Social Forces. 71(4):1027-55.

Epstein, Debbie; Mendick, Heather; Moreau, Marie-Pierre. 2010; Imagining the Mathematician: Young People Talking about Popular Representations of Maths. Discourse: Studies in the Cultural Politics of Education. 13(1):45-60.

Falci, Christina D. 2011; Self-Esteem and Mastery Trajectories in High School by Social Class and Gender. Social Science Research. 40(2):586-601. [PubMed: 21423844]

Farkas, George; Lleras, Christy; Maczuga, Steve. 2002; Does Oppositional Culture Exist in Minority and Poverty Peer Groups? American Sociological Review. 67(1):148-55. 
Fletcher, Jason M. 2015; Social Interactions and College Enrollment: A Combined School Fixed Effects/Instrumental Variables Approach. Social Science Research. 52:494-507. [PubMed: 26004476]

Frazier, Patricia; Keenan, Nora; Anders, Samantha; Perera, Sulani; Shallcross, Sandra; Hintz, Samuel. 2011; Perceived Past, Present, and Future Control and Adjustment to Stressful Life Events. Journal of Personality and Social Psychology. 100(4):749-65. [PubMed: 21299308]

Freese, Jeremy; Brian, Powell. 2003; Tilting at Twindmills: Rethinking Sociological Responses to Behavioral Genetics. Journal of Health and Social Behavior. 44(2):130-35. [PubMed: 12866385]

Gamoran, Adam; Long, Daniel A. Equality of Educational Opportunity: A 40-Year Retrospective. Madison, WI: University of Wisconsin-Madison; 2006. WCER Working Paper No. 2006-9

Gan, Yiqun; Shang, Jiayin; Zhang, Yiling. 2007; Coping Flexibility and Locus of Control as Predictors of Burnout among Chinese College Students. Social Behavior \& Personality: An International Journal. 35(8):1087-98.

Gándara, Patricia. Over the Ivy Walls - The Educational Mobility of Low-Income Chicanos. Albany, NY: State University of New York Press; 1995.

Garcia, Emma. The Need to Address Noncognitive Skills in the Education Policy Agenda. Washington, DC: Economic Policy Institute; 2015. Briefing Paper \#386

Gastic, Billie. 2010; Metal Detectors and Feeling Safe at School. Education and Urban Society. 43(4): 486-98.

Gecas, Viktor. 1989; The Social Psychology of Self-Efficacy. Annual Review of Sociology. 15:291316.

Gecas, Viktor; Schwalbe, Michael L. 1983; Beyond the Looking-Glass Self: Social Structure and Efficacy-Based Self-Esteem. Social Psychology Quarterly. 46(2):77-88. [PubMed: 6879222]

Gecas, Viktor; Seff, Monica A. 1990; Families and Adolescents: A Review of the 1980s. Journal of Marriage and Family. 52(4):941-58.

Glavin, Paul; Scott, Schieman. 2014; Control in the Face of Uncertainty: Is Job Insecurity a Challenge to the Mental Health Benefits of Control Beliefs? Social Psychology Quarterly. 77(4):319-43.

Gould, Stephen J. 1999; A Critique of Heckhausen and Schulz's (1995) Life-Span Theory of Control From a Cross-Cultural Perspective. Psychological Review. 106(3):597-604.

Gregoire, Michele; Algina, James. Reconceptualizing the Debate on School Climate and Students' Academic Motivation and Achievement: A Multilevel Analysis. American Educational Research Association; New Orleans, LA: 2000.

Grolnick, Wendy S; Ryan, Richard M. 1989; Parent Styles Associated with Children's Self-Regulation and Competence in School. Journal of Educational Psychology. 81(2):143-54.

Gross, Elisheva F. 2004; Adolescent Internet Use: What We Expect, What Teens Report. Applied Developmental Psychology. 25:633-40.

Gurin, Patricia; Gurin, Gerald; Morrison, Betty M. 1978; Personal and Ideological Aspects of Internal and External Control. Social Psychology. 41(4):275-96.

Haertel, Edward. SCOPE Brown Bag Seminars. Graduate School of Education,Stanford University; Stanford, CA: 2013. Using Student Test Scores to Compare Teachers.

Halaby, Charles N. 2004; Panel Models in Sociological Research: Theory into Practice. Annual Review of Sociology. 30:507-44.

Hango, Darcy. 2007; Parental Investment in Childhood and Educational Qualifications: Can Greater Parental Involvement Mediate the Effects of Socioeconomic Disadvantage? Social Science Research. 36(4):1371-90.

Hanushek, Eric A; Kain, John F; Rivkin, Steven G. 2009; New Evidence about Brown v. Board of Education: The Complex Effects of School Racial Composition on Achievement. Journal of Labor Economics. 27(3):349-83.

Healy, Kieran; Moody, James. 2014; Data Visualization in Sociology. Annual Review of Sociology. 40:105-28.

Heidemeier, Heike; Goritz, Anja S. 2013; Perceived Control in Low-Control Circumstances: Control Beliefs Predict a Greater Decrease in Life Satisfaction Following Job Loss. Journal of Research in Personality. 47(1) 
Hill, Heather C. 201650 Years Ago, One Report Introduced Americans to the Black-White Achievement Gap. Here's What We've Learned Since. Chalkbeat.

Hoffman, Diane M. 2010; Risky Investments: Parenting and the Production of the 'Resilient Child'. Health, Risk \& Society. 12(4):385-94.

Ingels, Steven J, Leslie, Scott; Judith, Lindmark; Frankel, Martin R, Myers, Sharon. National Education Longitudinal Study of 1988 First Follow-Up: Student Component Data File User's Manual. Washington, DC: U.S. Department of Education; 1992.

Jaffee, Sara R; Moffitt, Terrie E; Caspi, Avshalom; Taylor, Alan. 2003; Life With (or Without) Father: The Benefits of Living With Two Biological Parents Depend on the Father's Antisocial Behavior. Child Development. 74(1):109-26. [PubMed: 12625439]

Judge, Timothy A; Erez, Amir; Bono, Joyce E; Thoresen, Carl J. 2002; Are Measures of Self-Esteem, Neuroticism, Locus of Control, and Generalized Self-Efficacy Indicators of a Common Core Construct? Journal of Personality and Social Psychology. 83(3):693-710. [PubMed: 12219863]

Kalil, Ariel; DeLeire, Thomas. Parental Job Loss and Early Adolescent Adjustment in Black and White Families. Chicago, IL: Joint Center for Poverty Research, I. L.; 2002. JCPR Working Paper

Karlson, Kristian Bernt. 2015Expectations on Track? High School Tracking and Adolescent Educational Expectations. Social Forces.

Katz, James E, Rice, Ronald E. Social Consequences of Internet Use: Access, Involvement, and Interaction. Cambridge, MA: The MIT Press; 2002.

Kelly, Sean. 2004; Do Increased Levels of Parental Involvement Account for Social Class Differences in Track Placement? Social Science Research. 33:626-59.

Kerr, Margaret; Stattin, Hakan; Burk, William J. 2010; A Reinterpretation of Parental Monitoring in Longitudinal Perspective. Journal of Research on Adolescence. 20(1):39-64.

Kiviruusu, Olli; Huurre, Taina; Haukkala, Ari; Aro, Hillevi. 2013; Changes in Psychological Resources Moderate the Effect of Socioeconomic Status on Distress Symptoms: A 10-Year Follow-Up Among Young Adults. Health Psychology. 32(6):627-36. [PubMed: 22924450]

Kohler, Ulrich; Karlson, Kristian Bernt; Holm, Anders. 2011; Comparing Coefficients of Nested Nonlinear Probability Models. The Stata Journal. 11(3):420-38.

Kraus, Michael W; Piff, Paul K; Keltner, Dacher. 2009; Social Class, Sense of Control, and Social Explanation. Journal of Personality and Social Psychology. 97(6):992-1004. [PubMed: 19968415]

Krieger, Nancy; Williams, David R; Moss, Nancy E. 1997; Measuring Social Class in US Public Health Research: Concepts, Methodologies, and Guidelines. Annual Review of Public Health. 18(1):341-78.

Kroger, Jane. Identity Development during Adolescence. In: Kroger, Jane, editor. Identity Development: Adolescence Through Adulthood. Los Angeles, CA: Sage Publications, Inc; 2007. 205-26.

Lachman, Margie E; Weaver, Suzanne L. 1998; The Sense of Control as a Moderator of Social Class Differences in Health and Well-Being. Journal of Personality and Social Psychology. 74(3):76373. [PubMed: 9523418]

Lareau, Annette. 1987; Social Class Differences in Family-School Relationships: The Importance of Cultural Capital. Sociology of Education. 60(2):73-85.

Lareau, Annette. Unequal Childhoods: Class, Race, and Family Life. Berkeley, CA: University of California Press; 2003.

Lever, Joaquina Palomar; Pinol, Nuria Lanzagorta; Uralde, Jorge Hernandez. 2005; Poverty, Psychological Resources And Subjective Well-Being. Social Indicators Research. 73(3):375-408.

Livingstone, Sonia. 2008; Taking Risky Opportunities in Youthful Content Creation: Teenagers' Use of Social Networking Sites for Intimacy, Privacy and Self-Expression. New Media \& Society. 10(3): 393-411.

Mabry, J Beth; Jill Kiecolt, K. 2005; Anger in Black and White: Race, Alienation, and Anger. Journal of Health and Social Behavior. 46(1):85-101. [PubMed: 15869122]

Madon, Stephanie; Jussim, Lee; Eccles, Jacquelynne. 1997; In Search of the Powerful Self-Fulfilling Prophecy. Journal of Personality and Social Psychology. 72(4):791-809. [PubMed: 9108695] 
Manning, Wendy D; Smock, Pamela J; Majumdar, Debarun. 2004; The Relative Stability of Cohabiting and Maritual Unions for Children. Population Research and Policy Review. 23(2):13559.

Maqsud, Muhammad; Rouhani, Sepideh. 1991; Relationships between Socioeconomic Status, Locus of Control, Self-Concept, and Academic Achievement of Batswana Adolescents. Journal of Youth and Adolescence. 20(1):107-14. [PubMed: 24264919]

Marin, Kelly A; Bohanek, Jennifer G; Fivush, Robyn. 2008; Positive Effects of Talking About the Negative: Family Narratives of Negative Experiences and Preadolescents' Perceived Competence. Journal of Research on Adolescence. 18(3):573-93.

Marks, Lawrence I. 1998; Deconstructing Locus of Control: Implications for Practitioners. Journal of Counseling \& Development. 76(3):251-60.

Martin, Molly A. 2006; Family Structure and Income Inequality in Families With Children, 1976 to 2000. Demography. 43(3):421-45. [PubMed: 17051821]

Matjasko, Jennifer L; Grunden, Leslie N; Ernst, Jody L. 2007; Structural and Dynamic Process Family Risk Factors: Consequences for Holistic Adolescent Functioning. Journal of Marriage and Family. 69:654-74.

McLeod, Jane D; Hallett, Tim; Lively, Kathryn J. 2015; Beyond Three Faces: Toward an Integrated Social Psychology of Inequality. Advances in Group Processes. 32(1):1-29.

McNeal, Ralph B, Jr. 1999; Parent Involvement as Social Capital: Differential Effectiveness on Science Achievement, Truancy, and Dropping Out. Social Forces. 78:117-44.

McNeal, Ralph B, Jr. 2001; Differential Effects of Parental Involvement on Cognitive and Behavioral Outcomes by Socioeconomic Status. Journal of Socioeconomic. 30:171-79.

Menaghan, Elizabeth G; Parcel, Toby L. 1991; Determining Children's Home Environments: The Impact of Maternal Characteristics and Current Occupational and Family Conditions. Journal of Marriage and Family. 53(2):417-31.

Miller, Peggy J; Su-hua, Wang; Sandel, Todd; Cho, Grace E. 2002; Self-Esteem as Folk Theory: A Comparison of European American and Taiwanese Mothers' Beliefs. Parenting: Science \& Practice. 2(3):209.

Mirowsky, John; Ross, Catherine E. 1983; Paranoia and the Structure of Powerlessness. American Sociological Review. 48:228-39. [PubMed: 6859680]

Mirowsky, John; Ross, Catherine E. 1991; Eliminating Defense and Agreement Bias from Measures of the Sense of Control: A $2 \times 2$ Index. Social Psychology Quarterly. 54(2):127-45.

Mirowsky, John; Ross, Catherine E; Van Willigen, Marieke. 1996; Instrumentalism in the Land of Opportunity: Socioeconomic Causes and Emotional Consequences. Social Psychology Quarterly. 59(4):322-37.

Mittal, Chiraag; Griskevicius, Vladas. 2014; Sense of Control Under Uncertainty Depends on People's Childhood Environment: A Life History Theory Approach. Journal of Personality and Social Psychology. 107(4):621-37. [PubMed: 25133717]

Moilanen, Kristin L; Shen, Yuh-Ling. 2014; Mastery in Middle Adolescence: The Contributions of Socioeconomic Status, Maternal Mastery and Supportive-Involved Mothering. Journal of Youth and Adolescence. 43:298-310. [PubMed: 23605690]

Mortimer, Jeylan T; Finch, Michael D. 1986; The Development of Self-Esteem in the Early Work Career. Work and Occupations. 13(2):217-39.

Neckerman, Kathryn M; Torche, Florencia. 2007; Inequality: Causes and Consequences. Annual Review of Sociology. 33:335-57.

Noguera, Pedro A. The Trouble with Black Boys: And Other Reflections on Race, Equity, and the Future of Public Education. San Francisco, CA: John Wiley and Sons; 2008.

O'Keeffe, Gwenn Schurgin; Clarke-Pearson, Kathleen; Council on Communications and Media. 2011; Clinical Report--The Impact of Social Media on Children, Adolescents, and Families. Pediatrics. 3(28):800-04.

Oakes, Michael. Measuring Socioeconomic Status. Rockville, MD: Office of Behavioral \& Social Sciences Research, National Institutes of Health; 2017.

Oliver, Melvin L, Shapiro, Thomas M. Black Wealth/White Wealth: New Perspective on Racial Inequality. New York, NY: Taylor \& Francis Group, LLC; 2006 [1995]. 
Orfield, Gary. 2014; Tenth Annual Brown Lecture in Education Research: A New Civil Rights Agenda for American Education. Educational Researcher. 43(6):273-92.

Orfield, Gary; Frankenberg, Erica; Ee, Jongyeon; Kuscera, John. Brown at 60: Great Progress, a Long Retreat and an Uncertain Future. Los Angeles, CA: The Civil Rights Project, University of California, Los Angeles; 2014.

Pals, Heili; Love, Tony P; Hannibal, Bryce; Waren, Warren. 2016; The Consequences of School Environment and Locus of Control on Adulthood Deviant Behavior. Deviant Behavior. 37(9): 1003-22.

Perna, Laura Walter; Titus, Marvin A. 2005; The Relationship between Parental Involvement as Social Capital and College Enrollment: An Examination of Racial/Ethnic Group Differences. The Journal of Higher Education. 76(5):485-518.

Reardon, Sean F. Whither Opportunity? Rising Inequality, Schools, and Children's Life Chances. New York, NY: Russell Sage Foundation; 2011. The Widening Academic Achievement Gap Between the Rich and the Poor: New Evidence and Possible Explanations.

Roberts, Brent W; Wood, Dustin; Smith, Jennifer L. 2005; Evaluating Five Factor Theory and Social Investment Perspectives on Personality Trait Development. Journal on Research in Personality. 39(1):166-84.

Romagnoli, Amy; Glenda, Wall. 2012; 'I Know I'm a Good Mom': Young, Low-Income Mothers' Experiences with Risk Perception, Intensive Parenting Ideology and Parenting Education Programmes. Health, Risk \& Society. 14(3):273-89.

Ross, Catherine E; Broh, Beckett A. 2000; The Roles of Self-Esteem and the Sense of Personal Control in the Academic Achievement Process. Sociology of Education. 73(4):270-84.

Ross, Catherine E; Mirowsky, John. 1992; Households, Employment, and the Sense of Control. Social Psychology Quarterly. 55(3):217-35.

Ross, Catherine E, Mirowsky, John. The Sense of Personal Control: Social Structural Causes and Emotional Consequences. In: Aneshensel, Carol S, Phelan, Jo C, Bierman, Alex, editors. Handbook of the Sociology of Mental Health. Second. Dordrecht, Netherlands: Springer Science +Business Media; 2013. 379-404.

Ross, Catherine E; Mirowsky, John; Cockerham, William C. 1983; Social Class, Mexican Culture, and Fatalism: Their Effects on Psychological Distress. American Journal of Community Psychology. 11(4):383-99. [PubMed: 6637901]

Ross, Catherine E, Sastry, Jaya. The Sense of Personal Control: Social-Structural Causes and Emotional Consequences. In: Aneshensel, Carol S, Phelan, Jo C, editors. Handbook of the Sociology of Mental Health. New York, NY: Kluwer Academic/Plenum Publishers; 1999. 369_ 94.

Ross, Catherine E; Van Willigen, Marieke. 1997; Education and the Subjective Quality of Life. Journal of Health and Social Behavior. 38(3):275-97. [PubMed: 9343965]

Rotter, Julian B. Social Learning and Clinical Psychology. Englewood Cliffs, NJ: Prentice-Hall; 1954.

Ruggiero, Karen M; Taylor, Donald M. 1997; Why Minority Group Members Perceive or Do Not Perceive the Discrimination That Confronts Them: The Role of Self-Esteem and Perceived Control. Journal of Personality and Social Psychology. 72(2):373-89. [PubMed: 9107006]

Sastry, Jaya; Ross, Catherine E. 1998; Asian Ethnicity and the Sense of Personal Control. Social Psychology Quarterly. 61(2):101-20.

Schieman, Scott; Nguyen, Kim; Elliott, Diana. 2003; Religiosity, Socioeconomic Status, and the Sense of Mastery. Social Psychology Quarterly. 66(3):202-21.

Schieman, Scott; Pudrovska, Tetyana; Pearlin, Leonard I; Ellison, Christopher G. 2006; The Sense of Divine Control and Psychological Distress: Variations Across Race and Socioeconomic Status. Journal for the Scientific Study of Religion. 45(4):529-49.

Schradie, Jen. 2012; The Trend of Class, Race, and Ethnicity in Social Media Inequality. Information, Communication \& Society. 15(4):555-71.

Sechrist, Gretchen B; Swim, Janet K; Stangor, Charles. 2004; When Do the Stigmatized Make Attributions to Discrimination Occurring to the Self and Others? The Roles of Self-Presentation and Need for Control. Journal of Personality and Social Psychology. 87(1):111-22. [PubMed: 15250796] 
Shifrer, Dara; Sutton, April. 2014; Region-Urbanicity Differences in Locus of Control: Social Disadvantage, Structure, or Cultural Exceptionalism? Sociological Inquiry. 84(4):570-600. [PubMed: 25382875]

Shirani, Fiona; Henwood, Karen; Coltart, Carrie. 2012; Meeting the Challenges of Intensive Parenting Culture: Gender, Risk Management and the Moral Parent. Sociology. 46(1):25-40.

Stewart, Endya B. 2008; School Structural Characteristics, Student Effort, Peer Associations, and Parental Involvement: The Influence of School- and Individual-Level Factors on Academic Achievement. Education and Urban Society. 40(2):179-204.

Stokes, Charles E; Regnerus, Mark D. 2009; When Faith Divides Family: Religious Discord and Adolescent Reports of Parent-Child Relations. Social Science Research. 38(1):155-67. [PubMed: 19569298]

Subrahmanyam, Kaveri; Greenfield, Patricia; Kraut, Robert; Gross, Elisheva. 2001; The Impact of Computer Use on Children's and Adolescents' Development. Applied Developmental Psychology. 22(1):7-30.

Suh, Suhyun; Suh, Jingyo. 2006; Educational Engagement and Degree Attainment among High School Dropouts. Educational Research Quarterly. 29(3):11-20.

Sui-Chu, Esther Ho; Willms, J Douglas. 1996; Effects of Parental Involvement on Eighth-Grade Achievement. Sociology of Education. 69(2):126-41.

Thompson, Suzanne C; Nanni, Christopher; Levine, Alexandra. 1994; Primary Versus Secondary and Central Versus Consequence-Related Control in HIV-Positive Men. Journal of Personality and Social Psychology. 67(3):540-47. [PubMed: 7965603]

Tough, Paul. Whatever It Takes: Geoffrey Canada's Quest to Change Harlem and America. Boston, MA: Mariner Books; 2008.

Tourangeau, Roger; Yan, Ting. 2007; Sensitive Questions in Surveys. Psychological Bulletin. 133(5): 859-83. [PubMed: 17723033]

Valkenburg, Patti M; Peter, Jochen. 2009; Social Consequences of the Internet for Adolescents: A Decade of Research. Current Direction. 18(1):1-5.

Vitaro, Frank; Tremblay, Richard E; Kerr, Margaret; Pagani, Linda; Bukowski, William M. 1997; Disruptiveness, Friends' Characteristics, and Delinquency in Early Adolescence: A Test of Two Competing Models of Development. Child Development. 68(4):676-89. [PubMed: 9306646]

Ward, Michael M. 2013; Parental Educational Attainment and Sense of Control in Mid- and LateAdulthood. Developmental Psychology. 49(7):1407-12. [PubMed: 22889396]

Warren, John Robert; Halpern-Manners, Andrew. 2012; Panel Conditioning in Longitudinal Social Science Surveys. Sociological Methods \& Research. 41(1):491-534.

Western, Bruce; Rosenfeld, Jake. 2011; Unions, Norms, and the Rise in U.S. Wage Inequality. American Sociological Review. 76(4):513-37.

Whitbeck, Les B; Simons, Ronald L; Conger, Rand D; Wickrama, KAS; Ackley, Kevin A; Elder, Glen H, Jr. 1997; The Effects of Parents' Working Conditions and Family Economic Hardship on Parenting Behaviors and Children's Self-Efficacy. Social Psychology Quarterly. 60(4):291-303.

White, Ian R; Royston, Patrick; Wood, Angela M. 2011; Multiple Imputation Using Chained Equations: Issues and Guidance for Practice. Statistics in Medicine. 30(4):377-99. [PubMed: 21225900]

Williams, David R; Priest, Naomi; Anderson, Norman. 2016; Understanding Associations between Race, Socioeconomic Status and Health: Patterns and Prospects. Health Psychology. 35(4):40711. [PubMed: 27018733]

Wohlfarth, Tamar. 1997; Socioeconomic Inequality and Psychopathology: Are Socioeconomic Status and Social Class Interchangeable? Social Science \& Medicine. 45(3):399-410. [PubMed: 9232734]

Wolfle, Lee M; List, Jill H. 2004; Temporal Stability in the Effects of College Attendance on Locus of Control, 1972-1992. Structural Equation Modeling: A Multidisciplinary Journal. 11(2):244-60.

York, Benjamin N, Susanna, Loeb. One Step at a Time: The Effects of an Early Literacy Text Messaging Program for Parents of Preschoolers. Cambridge, MA: National Bureau of Economic Research; 2014. 
Zytkoskee, Adrian; Strickland, Bonnie R; Watson, James. 1971; Delay of Gratification and Internal Versus External Control among Adolescents of Low Socioeconomic Status. Developmental Psychology. 4(1 Pt 1):93-98. 


\section{Table 1}

Part 1 of 2: Descriptive Statistics and the Association of Each Component of Socioeconomic Status with Adolescents' Locus of Control

\begin{tabular}{|c|c|c|c|c|}
\hline & Mean & SD & Range & $\underline{\text { F-ratio }}{ }^{a}$ \\
\hline 10th Grade Locus of Control & 0.01 & $(1.11)$ & {$[-4.41,2.40]$} & \\
\hline \multicolumn{5}{|l|}{ Socioeconomic Status } \\
\hline Parents' educational attainment: & & & & 64.4 \\
\hline High school or less & 0.30 & & & \\
\hline Some college & 0.42 & & & \\
\hline Bachelor's degree or higher & 0.28 & & & \\
\hline Family income & 9.64 & $(2.83)$ & {$[1,15]$} & 99.4 \\
\hline Parent(s) in professional occupation & 0.45 & & & 23.0 \\
\hline Race: & & & & 9.2 \\
\hline White, not Hispanic & 0.73 & & & \\
\hline Black, not Hispanic & 0.13 & & & \\
\hline Hispanic & 0.10 & & & \\
\hline Other race & 0.05 & & & \\
\hline \multicolumn{5}{|l|}{ Parental Influences } \\
\hline Biological father and mother in $\mathrm{HH}$ & 0.60 & & & \\
\hline Number of cognitive resources in $\mathrm{HH}$ & 7.36 & $(2.06)$ & {$[0,10]$} & \\
\hline Number of material resources in $\mathrm{HH}$ & 4.88 & $(1.44)$ & {$[0,6]$} & \\
\hline \multicolumn{5}{|l|}{ Parental Involvement in Educational Matters } \\
\hline Discussions with parents about school & 4.14 & $(1.65)$ & {$[0,6]$} & \\
\hline Parental involvement at school & 2.01 & $(1.28)$ & {$[0,4]$} & \\
\hline Parents' educational expectations & 4.83 & $(1.19)$ & {$[0,3]$} & \\
\hline \multicolumn{5}{|l|}{ Religious Participation } \\
\hline Attends religious education class & 0.18 & & & \\
\hline Participates in religious organization & 0.15 & & & \\
\hline Participates in religious youth group & 0.34 & & & \\
\hline \multicolumn{5}{|l|}{ Frequency of Parental Disciplinary Control } \\
\hline Check on homework & 2.10 & $(1.08)$ & {$[0,3]$} & \\
\hline Require chores around the home & 2.56 & $(0.78)$ & {$[0,3]$} & \\
\hline Limit time spent watching TV & 1.14 & $(1.16)$ & {$[0,3]$} & \\
\hline Limit time going out with friends & 2.05 & $(1.09)$ & {$[0,3]$} & \\
\hline \multicolumn{5}{|l|}{ Prior Academic Experiences } \\
\hline English is student's native language & 0.91 & & & \\
\hline Ever retained as of 8 th grade & 0.17 & & & \\
\hline \multicolumn{5}{|l|}{ Average GPA between 6th and 8th grades in: } \\
\hline English & 2.94 & $(1.06)$ & {$[0,4]$} & \\
\hline Math & 2.92 & $(1.11)$ & {$[0,4]$} & \\
\hline Science & 2.82 & $(1.13)$ & {$[0,4]$} & \\
\hline Social Studies & 2.84 & $(1.16)$ & {$[0,4]$} & \\
\hline
\end{tabular}




\begin{tabular}{|c|c|c|c|c|}
\hline & Mean & SD & Range & $\underline{\text { F-ratio }} a$ \\
\hline In remedial English in 8th grade & 0.12 & & & \\
\hline In remedial math in 8 th grade & 0.08 & & & \\
\hline \multicolumn{5}{|l|}{ School Structure } \\
\hline \multicolumn{5}{|l|}{ Mentoring Opportunities } \\
\hline Student enrollment & 662.97 & $(403.41)$ & {$[38,3940]$} & \\
\hline Teacher to student ratio & 0.06 & $(0.02)$ & {$[0.02,0.20]$} & \\
\hline Proportion teachers with grad degree & 0.47 & $(0.27)$ & {$[0.00,1.00]$} & \\
\hline \multicolumn{5}{|l|}{ Personal Development Opportunities } \\
\hline Number extracurriculars available & 11.55 & $(4.43)$ & {$[1,22]$} & \\
\hline Proportion of students in job training & 0.01 & $(0.06)$ & {$[0.00,1.00]$} & \\
\hline \multicolumn{5}{|l|}{ Controlling Climate } \\
\hline Formal admission procedures & 0.80 & & & \\
\hline Degree discipline emphasized & 3.50 & $(0.92)$ & {$[0,4]$} & \\
\hline Minimum GPA to participate in activities & 0.76 & & & \\
\hline Number tests for grade promotion & 1.20 & $(1.76)$ & {$[0,7]$} & \\
\hline \multicolumn{5}{|l|}{ Peer Influences } \\
\hline Private school & 0.12 & & & \\
\hline Percent eligible for free lunch program & 23.99 & $(25.65)$ & {$[0,100]$} & \\
\hline Percent racial minority & 25.57 & $(33.60)$ & {$[0,100]$} & \\
\hline Degree friends are academically oriented & 4.90 & $(3.08)$ & {$[0,14]$} & \\
\hline \multicolumn{5}{|l|}{ Negative Peer Behavior } \\
\hline Other students often disrupt class & 1.97 & $(0.76)$ & {$[0,3]$} & \\
\hline Other students disrupt my learning & 1.35 & $(0.91)$ & {$[0,3]$} & \\
\hline Administrator perceives negative environment & 7.17 & $(4.72)$ & {$[0,30]$} & \\
\hline \multicolumn{5}{|l|}{ Negative Peer Interactions } \\
\hline Someone threatened to hurt & 0.34 & $(0.64)$ & {$[0,2]$} & \\
\hline Had something stolen & 0.57 & $(0.70)$ & {$[0,2]$} & \\
\hline Don't feel safe at this school & 0.76 & $(0.81)$ & {$[0,3]$} & \\
\hline Adolescents (n) & & & & 16,450 \\
\hline
\end{tabular}

Note: $\mathrm{HH}=$ household. $\mathrm{SD}=$ standard deviation. $\mathrm{GPA}=$ grade point average.

F-ratios are from a fixed-intercept linear regression model predicting adolescents' locus of control with all four SES components. Coefficients from full model available in Online Table 4. In a model using the alternate measure of parent occupation (see Online Table 4), the f-ratios for each SES component were similar to those in this table, with family income associating most closely with adolescent locus of control and race associating least closely. 


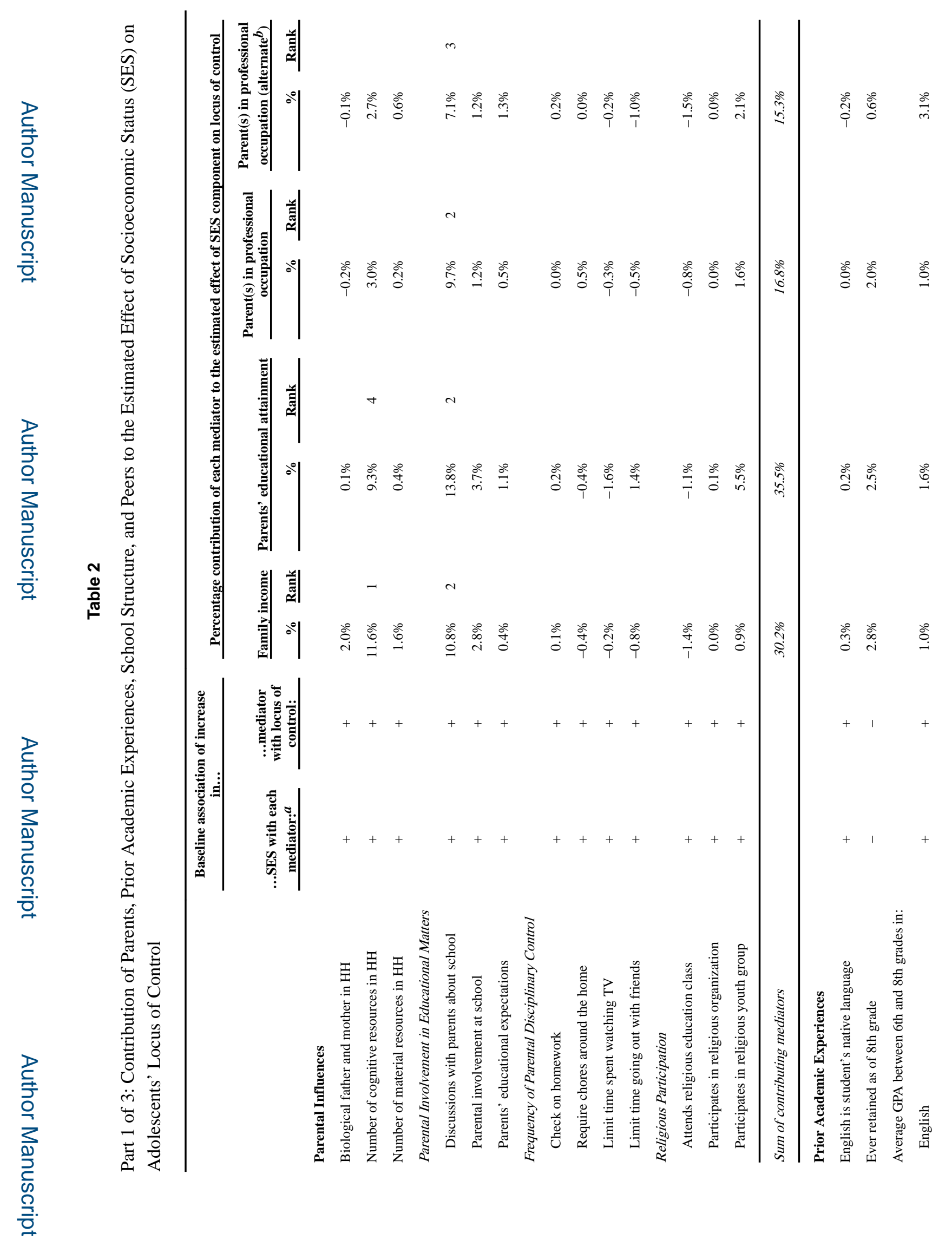

Soc Ment Health. Author manuscript; available in PMC 2019 March 05. 


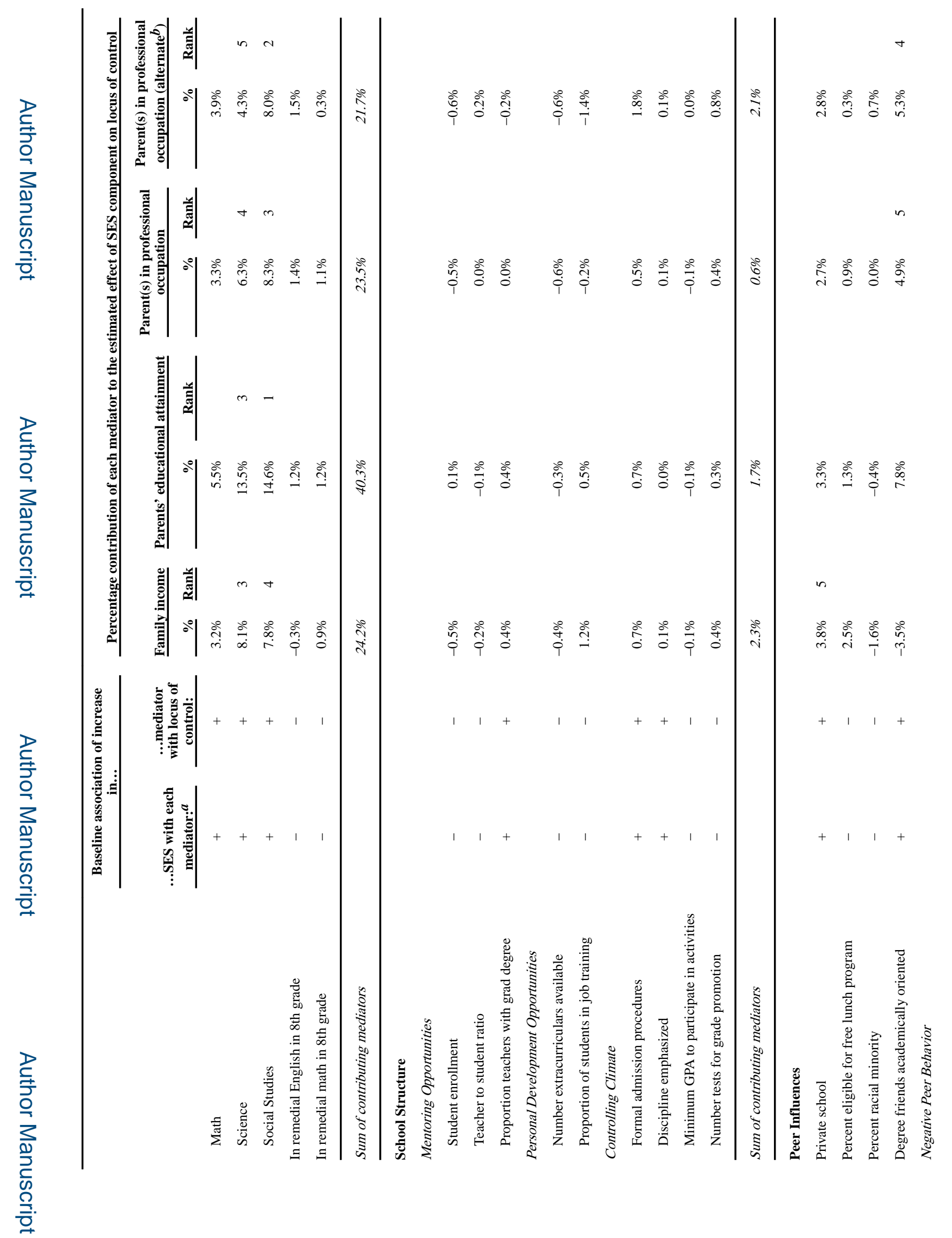

Soc Ment Health. Author manuscript; available in PMC 2019 March 05. 


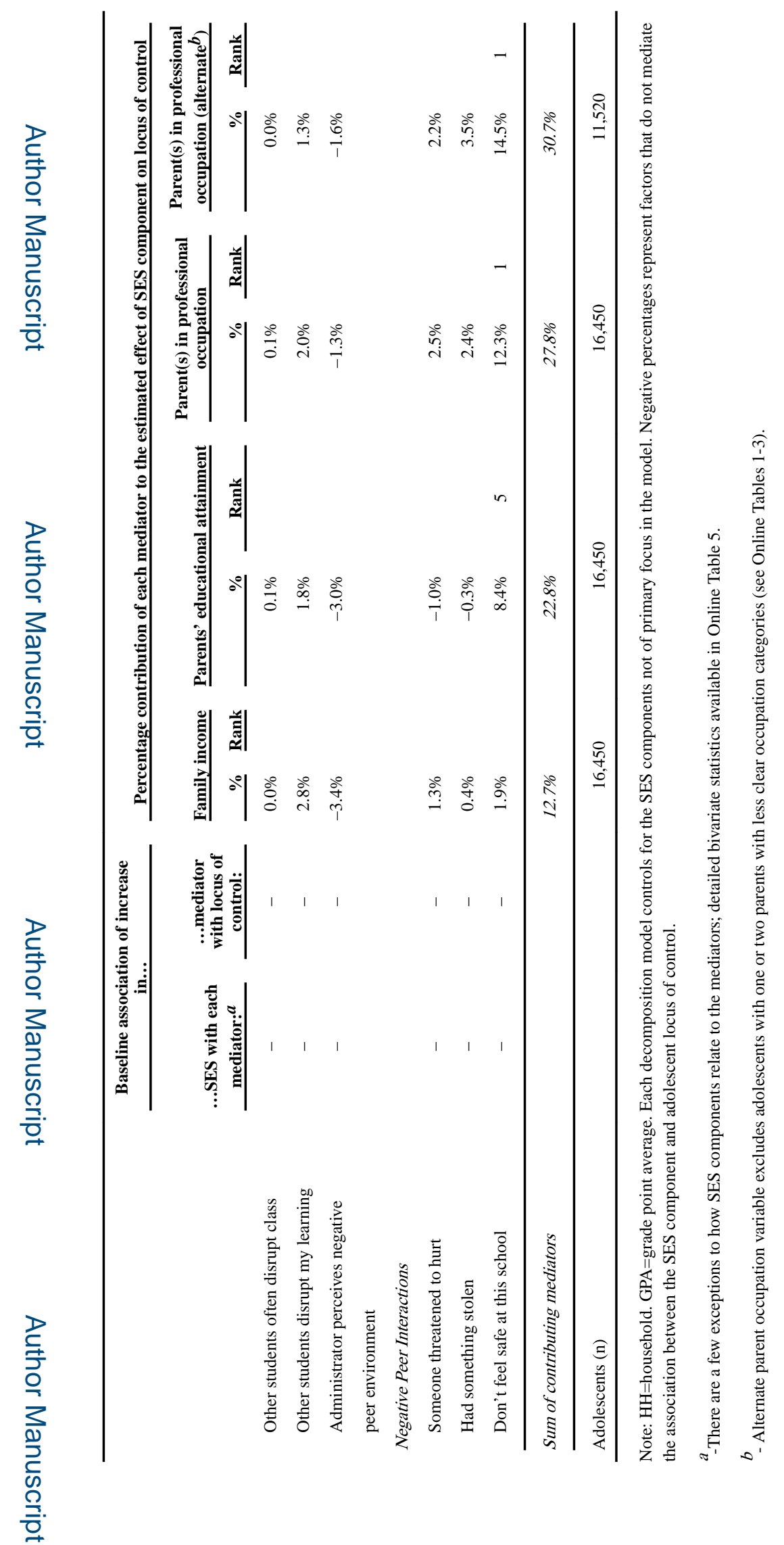

Soc Ment Health. Author manuscript; available in PMC 2019 March 05. 